\title{
Cohort Differences in Personal Goals and Life Satisfaction in Young Adulthood: Evidence for Historical Shifts in Developmental Tasks
}

\author{
Franciska Krings • Adrian Bangerter · \\ Veronica Gomez · Alexander Grob
}

Published online: 28 May 2008

(C) Springer Science+Business Media, LLC 2008

\begin{abstract}
This study investigated the influence of changing socio-historical conditions on personal goals in young adulthood. It was hypothesized that socio-historical changes related to individualization have resulted in shifts in goal pursuit. Participants from three birth cohorts reconstructed their important goals when they were 20 years old. Members of the oldest cohort were born between 1920 and 1925. Members of the middle cohort were born between 1945 and 1950. Members of the youngest cohort were born between 1970 and 1975. Goal content, the degree to which goals were perceived as being shared by members of the same cohort (social sharedness), perceived control over goal attainment, success in attainment, and life satisfaction at age 25 were measured in a retrospective study. Results show consistent shifts over time. Whereas members of older cohorts mentioned goals related to classical developmental tasks, members of younger cohorts mentioned more individualistic, self-related goals and goals related to education. The processes through which goal pursuit influenced life satisfaction also changed. Perceived social sharedness of goals was a direct predictor of life satisfaction for the oldest cohort. For the younger cohorts, perceived control over goal attainment
\end{abstract}

F. Krings ( $\square)$

Faculty of Business and Economics (HEC), University of Lausanne, Internef, Office 613, 1015 Lausanne-Dorigny, Switzerland

e-mail: franciska.krings@unil.ch

\section{A. Bangerter}

Institut de Psychologie du Travail et des Organisations,

University of Neuchâtel, Neuchatel, Switzerland

V. Gomez · A. Grob

Institut für Psychologie, University of Basel, Basel, Switzerland influenced success which in turn influenced life satisfaction. These changes support the contention that developmental tasks and processes are historically variant.

Keywords Young adulthood Personal goals ·

Socio-historical context

\section{Introduction}

Goal concepts are central for psychology in general (Austin and Vancouver 1996) and for development in particular. The developmental perspective underscores the importance of motivation and life goals for developmental regulation over the life span (e.g., Brandtstädter 1984; Heckhausen 1999). Goals are future-oriented representations of what individuals try to attain or to avoid in different life domains (Brunstein et al. 1999). By setting and pursuing personal goals, individuals take an active part in their developmental course, beyond the impact of internal drives and environmental constraints. Possessing and pursuing important personal goals promote subjective well-being and life satisfaction throughout the life span (Diener et al. 1999).

Although much is known about structure, process and content of goals (Austin and Vancouver 1996), less is known about where they come from. It has often been acknowledged that goals are subject to environmental factors that shape conditions of goal setting and pursuit (Little 1989; Smith 1996). However, there has been little empirical research on these factors. Our study addresses this question. Its purpose was to show how the relations between personal goals and well-being in young adulthood vary according to a particular environmental factor: the socio-historical context. In a retrospective cross-sectional study, we examined personal goals and life satisfaction in young adulthood of 
participants from three cohorts born between 1920 and 1975. Young adulthood is a particularly interesting testbed for studying how socio-historical factors influence goals. During this period, many goals that are central for personal development in adulthood are first formed (Arnett 2000). More importantly, however, this period of the life span has evolved very much over the past century. In what follows, we analyze changing socio-historical conditions and their impact on developmental tasks of young adulthood, derive hypotheses about changes in the goal content and processes of young adults from different historical time periods and describe a study designed to test these hypotheses. We start with an overview of the importance of socio-historical context in developmental regulation.

\section{The Socio-Historical Context of Goal Setting and Goal Pursuit}

Developmental regulation and thus, goal setting is influenced by external constraints and opportunities that structure the life course (Heckhausen 1999; Mayer 2004). Those contextual influences comprise age-graded, normative influences (genetic-biological and society-related), historical influences, and non-normative influences (events that are not age-related, that are experienced by few individuals with low probability) (Baltes et al. 1980). The focus of the present study is the interaction between age-graded and historical influences. Typical examples of age-graded normative influences on goal setting are developmental tasks, i.e., tasks that individuals have to master at specific ages (Havighurst 1948). They represent developmental norms by structuring the life course into a sequence of age-graded goals. The question arises whether these norms are valid from one generation to the next or whether they vary historically. Many developmental psychology textbooks (e.g., Coleman and Hendry 1999; Oerter and Montada 1998) seem to assume that they are invariant, often citing developmental tasks of young adulthood that were originally formulated by Havighurst in 1948. However, developmental tasks derive partly from agenormative developmental expectations shared by members of a given society (Heckhausen and Krüger 1993; Settersten 1997), and those expectations do change as a function of historical time (Hareven 1986; Riley 1986). In particular, during the past century, Western societies have undergone profound changes, many of them related to individualization processes. The notion of the standardization and de-standardization of the life course (Held 1986; Kohli 1985, 2000) illustrates how deeply individualization has affected and still affects individual development. By this view, the life course has become increasingly structured along the dimension of chronological age, resulting in three major life periods: preparation for an occupation, working life, and retirement (Kohli 1985). Since the 1980s, several trends indicate that the standardized life course may be disintegrating (Brose 2003; Kohli 2000; Mayer 2004). The most dramatic changes have been observed in the domain of the family: families are founded later and later, birth and marriage rates have declined, whereas divorce rates and new forms of cohabitation have increased. But other domains have also been affected, for example the work domain. Notable changes include female labor force participation, part-time work, unemployment and self-employment. These changes have contributed to an increasing plurality in the organization of life-paths (Brose 2003; Mayer 2004). The life course today seems to have lost its structuring and normative character, i.e., it has become de-standardized.

As a consequence, for individual development in young adulthood today, traditional developmental tasks and goals seem to be less dictated by society and less bound to specific ages. Individual development and prescriptive norms about how to attain happiness have diversified. Moreover, young adults seem to be confronted with new developmental challenges such as the necessity to repeatedly realize themselves in an original manner. They may have to construct their own life course and find their own ways to personal happiness by choosing goals from a large array of possibilities and decide themselves on ways to realize them (Grob et al. 2001). Thus, it seems that the individualization processes may not only have diversified developmental pathways by changing young adults' developmental tasks (and thereby affecting goal content) but also by changing goal processes, i.e., paths of successful goal pursuit and ways to attain individual happiness. We examined these changes by analyzing how members of different cohorts reconstructed content (what were typical goals?) and processes (what were important factors of goal pursuit?) for personal goals at age 20 and how these processes related to life satisfaction at age 25 . We discuss socio-historical effects on content and process separately, and then outline the rationale of the study.

\section{Socio-Historical Influences on Goal Content in Young Adulthood}

From a life span perspective, goals of young adults are oriented toward "developmental gains" such as the expansion of resources and implementation of future projects (Heckhausen 1999). Goals of younger adults often reflect typical role transitions (Elder 1985) and developmental tasks of young adulthood such as completing education, getting started in an occupation and starting a family (Nurmi 1991, 1992). However, some recent studies 
indicate that these role transitions and developmental tasks are changing due to socio-historical influences such as an increase in affluence. Arnett $(1998,2000)$ argued that a new developmental period of "emerging adulthood" has developed in recent decades in Western societies. This period ranges from about ages 18-25 and is characterized by the independence of social roles and normative expectations and by extensive exploration of various forms of life in domains such as love, work, and world-views. These issues affect goal setting during this period. In one study, participants primarily endorsed individualistic criteria (qualities of character such as accepting responsibility for one's action or deciding on one's own beliefs and values) when asked which tasks have to be achieved before a person can be considered to be an adult, whereas classical role transitions such as marriage, parenthood or finishing an education received only low endorsement (Arnett 2001). In a qualitative study, Bangerter et al. (2001) found similar tendencies when comparing goals at age 25 of participants from three cohorts. Family-related (e.g., founding a family) and work-related goals (e.g., finding a job) declined from the oldest cohort to the youngest cohort. However, education and leisure-related goals increased from the oldest to the younger cohort. Similarly, Cohen and Cohen (2001) reported changes in life goals of adolescents over two decades. Adolescents showed an increasing preference for self-related (e.g., understanding oneself) and hedonistic goals (e.g., having an exciting life). However, self-related goals are not always beneficial. Goals focusing on the development of one's personality, identity, and life style are associated with low well-being (Salmela-Aro et al. 2001; see also Kasser and Ryan 1993). Taken together, research suggests that socio-historical context influences goal setting in young adulthood. The content of personal goals of young adults seems to have shifted from classical developmental tasks to a focus on the self.

\section{Socio-Historical Influences on Goal Processes in Young Adulthood}

What factors are important in goal pursuit and how are they related to well-being? Motivational approaches to psychological well-being assume that the pursuit of personal goals affect development and maintenance of individual well-being (Diener et al. 1999). The relation between goals and well-being has been demonstrated for various age groups (e.g., Diener and Fujita 1995; Diener et al. 1999; Lang and Heckhausen 2001; Lapierre et al. 1997; Palys and Little 1983). We discuss variables that have been identified as important for well-being and life satisfaction: perceived control over goal attainment, success in goal attainment, goal importance and the degree to which goals are perceived as being shared by similar others.

Perceived control over goal attainment is associated with well-being for both younger and older adults. This is consistent with the notion that sense of control over one's development promotes well-being throughout the life span (DeNeve and Cooper 1998; Grob et al. 1999). Similarly, Lang and Heckhausen (2001; study 3) found that perceived controllability of goal attainment was associated with life satisfaction in young, middle-aged and older adults. The more respondents perceived being able to influence goal attainment, the more they were satisfied with their lives. Moreover, higher perceived controllability was related to higher subjective success probability of goal attainment.

Perceived controllability may be moderated by goal importance or goal commitment. In a longitudinal study with young adults (Brunstein 1993), changes in well-being were best predicted by goal commitment and perceived goal attainability (e.g., personal control over goal attainment, favorability of conditions of goal attainment). However, goal commitment acted as a moderator: for young adults who felt strongly committed to their goals, high attainability led to more progress and to enhanced well-being. For respondents who were less committed to their goals, well-being was largely independent of goals and of perceptions of attainability. Similarly, Emmons (1986) found that goal importance and value were among the best predictors of different aspects of well-being: positive affect was most strongly predicted by goal value, past fulfillment, and effort investment, whereas life satisfaction was most strongly associated with goal importance, expected success and low likelihood of conflict. Thus, goal importance, perceived control over goal attainment and success in goal attainment seem closely related to psychological well-being (see also Emmons 1986, 1989).

Social support of goals also has a positive effect on wellbeing (Diener et al. 1999). The degree to which an individual's personal goals are shared by similar others indicates how well a goal is socially accepted. Pursuing a socially shared goal is more likely to receive social support, be rewarded with success and, consequently, to be beneficial for well-being than pursuing a non-shared goal. We refer to the degree to which an individual's personal goals are shared by members of the same cohort as 'social sharedness'. The term social sharedness was originally introduced by Tindale and Kameda (2000) to capture the degree to which motives, preferences, and cognitions are shared within a group.

Different cultural contexts indirectly prescribe different goals by defining happiness differently. Individualistic cultures emphasize personal achievement and heterogeneity, whereas collectivistic cultures emphasize interconnectedness and homogeneity (Uchida et al. 2004). These emphases may also reflect socio-historical trends. Increasing 
individualization may result in increasing prescriptions to be unique, thereby devaluing goals shared with others. Social sharedness may therefore be less predictive of life satisfaction in younger cohorts than in older ones. This may be compounded by the fact that self-related goals increase in younger cohorts. Being individualistic by definition, these goals may further diminish the importance of social sharedness over historical time.

In sum, research on goals and well-being has shown that variables such as perceived controllability, success, goal importance, and social sharedness are important precursors of subjective well-being and life satisfaction. However, the importance of those factors may vary as a function of sociohistorical change. For example, increasing individualization emphasizes the responsibility of the individual. Therefore, personal controllability of goal attainment should play a greater role for well-being in today's young adults than for older cohorts. By this logic, the role of social sharedness should also decrease from older to younger cohorts. In what follows, we outline our hypotheses in more detail.

\section{The Present Study}

Given the research summarized above, we designed a retrospective cross-sectional study with three birth cohorts. We asked them to report important goals they had when they were young adults. We expected to find cohort differences with respect to goal content and processes. Specifically, due to individualization processes during the last century, personal goals reported by older cohorts were expected to more closely match Havighurst's (1948) classical developmental tasks of young adulthood than those of younger cohorts. As a result of an increased emphasis on the self, members of younger cohorts were expected to report more self-related goals than participants of older cohorts.

Changing socio-historical conditions were also expected to influence perceptions of goal attributes. We expected people from younger cohorts to perceive themselves as agents in their lives to a greater extent than members of older cohorts (Grob et al. 2001). Consequently, perceived controllability of goal attainment was expected to increase from the oldest to the youngest cohort. Perceived social sharedness of goals, however, was expected to decrease from the oldest to the youngest cohort, due to decreasing societal consensus regarding appropriate goals over time.

Finally, socio-historical conditions were also estimated to affect regulation processes, i.e., the relation between goal attributes and well-being. Due to the greater focus on individual responsibility, for younger participants, control beliefs about goal attainability should be more closely related to success in goal attainment and individual wellbeing than for older participants. Perceived social sharedness of goals should influence success in goal attainment and well-being more for older than for younger participants. Goal success was expected to predict life satisfaction for all participants due to its strong relation to well-being in previous studies.

We studied three Swiss birth cohorts. Participants of the oldest cohort were born Between The first and second World War (BTW; born 1920-1925). They experienced late childhood and adolescence during a time of economic depression and young adulthood during World War II (although Switzerland was not occupied, it was nevertheless a time of hardship). Participants of the middle cohort were Early Baby Boomers (EBB; born 1940-1945) who experienced late adolescence and young adulthood during postwar economic growth, also coming of age during the women's rights movement and the civil unrest of the late 1960s. Participants of the youngest cohort were members of the so-called "GEneration X" (GEX; born 1970-1975). Their adolescence and young adulthood was characterized by affluence as well as an increasing awareness of ecological problems and of globalization. The birth years of these three cohorts were not chosen at random. The onset of young adulthood in these cohorts corresponds to pivotal societal changes in recent Swiss history, as exemplified in important events (e.g., World War II, civil unrest, globalization). These cohorts can thus be considered generations in Mannheim's (1952) sense, i.e., social groups whose members have experienced similar historical conditions of socialization and similar historical events. Moreover, the positioning of each cohort approximately 25 years apart makes them successive generations (members of a later generation are typically children of members of earlier generations) and thus ideal points of entry for assessing historical change and its effects on developmental goal setting.

Participants were asked to report their personal goals at age 20 and life satisfaction at age 25, and thus, engaged in a retrospective judgment process (see also Grundmann 1996, for a similar design). With this design, we studied how members of different cohorts reconstructed important goals and aspects of goal pursuit, that is, how people give meaning to the individual life course (McAdams 1996; Schroots and Assink 2005). Young adulthood is a particularly important period in this process of construction of a life story (Habermas and Bluck 2000), i.e., of a coherent account of one's own life in narrative form.

\section{Method}

\section{Participants}

All participants were Swiss citizens residing in urban and suburban regions in German-speaking Switzerland (cities of 
Berne and Basel). We excluded foreigners because of the nature of the study and the difficulty of controlling for different cultural and developmental contexts (e.g., immigration) in young adulthood. Potential participants were sampled randomly from address lists obtained from local authorities. The birth cohorts varied slightly between Berne and Basel regions. Birth year range of potential BTW participants was 1920-1925 in Berne and 1923-1925 in Basel (EBB Berne: 1945-1950; EBB Basel, 1948-1950; GEX Berne 1970-1975; GEX Basel: 1973-1975). At the time the study was conducted, BTW participants were approximately 75 years old. EBB participants were about 50 years old and GEX participants were about 25 years old.

Four thousand two hundred and thirty-six people were mailed a letter inviting them to participate in the study by filling out a questionnaire. Of these people, 766 returned a completed questionnaire (response rate $=18 \% ; 52 \%$ of respondents were women). They received CHF 20 each for participating. The response rate did not differ much by cohort, BTW: 266; EBB: 244; GEX: 256. Seventy percent of the BTW generation indicated secondary school as their highest level of educational qualification (EBB: 57\%, GEX: 34\%). Ninety-three percent of the BTW generation respondents had been married at least once or were married at the time of the study (EBB: $89 \%$, GEX: 10\%). The majority of participants of all cohorts $(90 \%)$ had lived in Switzerland since birth.

\section{Measures and Design}

Measures were part of a larger questionnaire that included questions on important events over the life span, goals, life satisfaction, and personality and demographic measures. Pilot studies indicated that it required approximately an hour to complete. Results reported here concern variables measured in the goals and life satisfaction sections for young adulthood $\left(n_{\text {total }}=749: n_{\mathrm{BTW}}=254, n_{\mathrm{EBB}}=240\right.$, $n_{\mathrm{GEX}}=255$ ). Participants were asked to describe up to three goals they pursued when they were approximately 20 years old, in a free-response format (e.g., "studying medicine"). They were instructed to note only the most important goals in order to control for variations in goal importance. They then evaluated each goal on three dimensions: success ("How successful were you at attaining this goal?"), controllability of goal attainment ("How much could you influence goal attainment by yourself?"), and social sharedness ("In your opinion, how many people of your age had a goal similar to yours at that time?"). Evaluations were made using five-point rating scales. Anchors were, for success, $1=$ not successful and $5=$ very successful, for control, $1=$ very little and $5=a$ lot, and for social sharedness, $1=$ very few and $5=$ almost all. We measured life satisfaction at age 25 . Life satisfaction is the cognitive component of subjective well-being and reflects a global assessment of one's life as a whole (Diener et al. 1999). It was operationalized using the following item: "How satisfied were you when you were about 25?" (eleven-point scale ranging from $-5=$ completely unsatisfied to $5=$ completely satisfied). Thus, in sum, members of the three cohorts reported contents and evaluations of goals at age 20 and life satisfaction at age 25 .

\section{Coding}

Participants mentioned 1,567 goals. They were coded for content according to 13 categories (work, education, family, marriage, health, values, self-related, material, relationships, leisure, housing, social participation, and other). Definitions and examples of each category are shown in Table 1. Interrater agreement was assessed by

Table 1 Content categories, definitions, and examples

\begin{tabular}{llll}
\hline & Category & Definition & Examples \\
\hline 1. & Work & Work, career, jobs & Getting a job, promotion \\
2. & Education & Starting or succeeding education & Getting a diploma \\
3. & Family & Family affairs (not including partners or friends) & Starting a family \\
4. & Marriage & Getting married & Marrying one's sweetheart \\
5. & Health & Looking after one's health & Staying fit \\
6. & Ideals/Values & Living according to ideals or values & Making a better world \\
7. & Self-related & Personal development and happiness & Being oneself, enjoying life to the fullest \\
8. & Material & Material possessions or money & Making money, buying a car \\
9. & Relationships & Relationships (including romantic) with non-family members & Finding a partner \\
10. & Leisure & Activities in leisure time & Traveling, learning English \\
11. & Housing & Living somewhere or moving & Moving out, living abroad \\
12. & Social participation & Affiliating with other & Being a useful member of society \\
13. & Other & None of the above categories & Surviving the war \\
\hline
\end{tabular}


double-coding $25 \%$ of the data (398 cases). Cohen's kappa statistic was computed and revealed high agreement $(\kappa=.87, p<.001)$.

\section{Results}

\section{Number of Goals Mentioned}

The mean number of goals mentioned by each person was subjected to a 3 (cohort) by 2 (sex) between-subjects ANOVA, which revealed a significant main effect of cohort, $F(2,669)=5.20, p<.01$, and a significant main effect of sex, $F(1,669)=7.17, p<.01$. Men $(M=2.38$, $\mathrm{SD}=.72)$ mentioned more goals than women $(M=2.26$, $\mathrm{SD}=.77)$. Post hoc tests (Tukey) on the first main effect revealed that BTW members $(M=2.20, \mathrm{SD}=.83)$ mentioned less goals than $\mathrm{EBB}(M=2.37, \mathrm{SD}=.76)$ or $\mathrm{GEX}$
$(M=2.38, \mathrm{SD}=.67)$ members. Therefore, for the following analyses, the number of goals mentioned by each person was weighted according to the total number of mentioned goals for each of the following six groups: BTW-men, BTW-women, EBB-men, EBB-women, GEXmen, and GEX-women.

\section{Goal Content}

Goal content was analyzed using a 3 (cohort) by 2 (sex) between-subjects multivariate analysis of variance with the weighted number of goals mentioned in the different categories as dependent variables. Results showed a significant effect of cohort (Pillai's Trace $=.39, F(30$, $1312)=10.77, p<.001)$, of gender (Pillai's Trace $=.11$, $F(15,655)=5.23, p<.001)$, and a cohort by gender interaction (Pillai's Trace $=.21, \quad F(30,1312)=5.24$, $p<.001$.) Univariate results are shown in Table 2 .

Table 2 Overview of cohort and gender differences in goal contents

\begin{tabular}{|c|c|c|c|c|c|c|c|c|}
\hline \multirow[t]{2}{*}{ Goal category } & \multicolumn{3}{|l|}{ Cohort (C) } & \multicolumn{3}{|l|}{ Gender (G) } & \multicolumn{2}{|l|}{$\mathrm{C} \times \mathrm{G}$} \\
\hline & $F(2,669)^{\mathrm{a}}$ & $\eta^{2}$ & Post hoc & $F(1,669)^{\mathrm{b}}$ & $\eta^{2}$ & Post hoc & $F(2,669)^{\mathrm{c}}$ & $\eta^{2}$ \\
\hline Work & $45.81 * *$ & .07 & $\begin{array}{l}\mathrm{BTW}>\mathrm{EBB} \\
\mathrm{BTW}>\mathrm{GEX} \\
\mathrm{EBB}>\mathrm{GEX}\end{array}$ & 0.21 & $<.01$ & & $4.83 * *$ & .01 \\
\hline Education & $6.95 * *$ & .01 & $\mathrm{EBB}<\mathrm{GEX}$ & $9.27 * *$ & .01 & $\mathrm{M}>\mathrm{W}$ & $7.99 * *$ & .01 \\
\hline Family & $59.81 * *$ & .11 & $\begin{array}{l}\mathrm{BTW}>\mathrm{EBB} \\
\mathrm{BTW}>\mathrm{GEX} \\
\mathrm{EBB}>\mathrm{GEX}\end{array}$ & $16.97 * *$ & .02 & $\mathrm{M}<\mathrm{W}$ & $4.09 *$ & .01 \\
\hline Marriage & $13.88 * *$ & .04 & $\begin{array}{l}\mathrm{BTW}>\text { GEX } \\
\mathrm{EBB}>\text { GEX }\end{array}$ & $24.88 * *$ & .03 & $\mathrm{M}<\mathrm{W}$ & $6.57 * *$ & .02 \\
\hline Health & 2.51 & .01 & & $3.90 *$ & .01 & $\mathrm{M}>\mathrm{W}$ & 0.50 & $<.01$ \\
\hline Ideals/Values & 2.50 & .01 & & 0.86 & $<.01$ & & 0.85 & $<.01$ \\
\hline Self-related & $4.52 *$ & .01 & $\begin{array}{l}\mathrm{BTW}<\mathrm{EBB} \\
\mathrm{BTW}<\mathrm{GEX}\end{array}$ & 0.47 & $<.01$ & & $3.55^{*}$ & .01 \\
\hline Material & 0.98 & $<.01$ & & $6.55^{*}$ & .01 & $\mathrm{M}>\mathrm{W}$ & 0.27 & $<.01$ \\
\hline Relationships & $28.35 * *$ & .06 & $\begin{array}{l}\mathrm{BTW}<\mathrm{EBB} \\
\mathrm{BTW}<\mathrm{GEX} \\
\mathrm{EBB}<\mathrm{GEX}\end{array}$ & $4.63 *$ & .01 & $\mathrm{M}>\mathrm{W}$ & $5.32 * *$ & .01 \\
\hline Leisure & 1.77 & $<.01$ & & 0.24 & $<.01$ & & 1.29 & $<.01$ \\
\hline Housing & $3.05^{*}$ & .01 & BTW < GEX & $9.06^{* *}$ & .01 & $\mathrm{M}<\mathrm{W}$ & 1.43 & $<.01$ \\
\hline Social participation & 0.67 & $<.01$ & & 0.02 & $<.01$ & & 2.39 & \\
\hline Other & $3.15^{*}$ & .01 & $\begin{array}{l}\mathrm{BTW}>\mathrm{EBB} \\
\mathrm{BTW}>\mathrm{GEX}\end{array}$ & $3.91 *$ & .01 & $\mathrm{M}>\mathrm{W}$ & 3.30 & .01 \\
\hline
\end{tabular}

Note: $\mathrm{M}=\mathrm{Men} ; \mathrm{W}=$ Women

${ }^{\text {a }}$ Pillai's Trace $.39, F(30,1312)=10.77, p<.001$

b Pillai's Trace $.11, F(15,655)=5.23, p<.001$

${ }^{c}$ Pillai's Trace $.21, F(30,1312)=5.24, p<.001$

$* p<.05$

$* * p<.01$ 
For work-related goals, there was a significant effect of cohort, $F(2,669)=45.81, p<.01$, and a significant cohort by gender interaction, $F(2,669)=4.83, p<.01$. Tukey post hoc tests of the cohort effect showed that BTW members mentioned more work-related goals than EBB and GEX members and EBB members mentioned more work-related goals than GEX members. Simple main effects analysis of the interaction revealed gender differences for the EBB cohort where men reported more workrelated goals than women, $F(1,669)=7.80, p<.01$. No gender differences emerged for the oldest and youngest cohort, both $F \mathrm{~s}<1.88, n s$.

For educational goals, the analysis yielded a main effect of cohort, $F(2,669)=6.95, p<.01$, of gender, $F(1$, $669)=9.27, p<.01$, and a significant cohort by gender interaction, $F(2,669)=7.99, p<.01$. Post hoc analysis of the cohort effect indicated that GEX members mentioned more educational goals than EBB members. The gender effect showed that men mentioned more educational goals than women. Finally, simple main effects analysis of the interaction showed that gender differences were confined to GEX participants, with GEX-men mentioning more educational goals than GEX-women, $F(1,669)=23.77, p<.01$. No gender differences were observed for the two older cohorts, both $F \mathrm{~s}<3.45$, ns. Further, differences between cohorts were found for men, with GEX-men mentioning more educational goals than BTW- and EBB-men, $F(2$, $669)=10.97, p<.01$, but not for women, $F<2.95, n s$.

For goals related to family, a main effect of cohort, $F(2$, $669)=59.81, p<.01$, of gender, $F(1,669)=16.97$, $p<.01$, as well as an interaction between cohort and gender were found, $F(2,669)=4.09, p<.01$. Post hoc tests of the first main effect revealed that family goals decreased from the oldest to the youngest cohort. The gender effect showed that women reported more familyrelated goals than men did. Simple main effects analysis of the interaction indicated that the gender effect was confined to the BTW cohort, with BTW-women mentioning more of these goals than men, $F(1,669)=18.85, p<.01$. No gender differences were found for the two younger cohorts, both $F$ s $<3.53$, ns.

A similar picture emerged for goals related to marriage, i.e., a main effect of cohort, $F(2,669)=13.88, p<.01)$, of gender, $F(1,669)=24.88, p<.01$, and interaction between cohort and gender, $F(2,669)=6.57, p<.01$. Post hoc analysis of the cohort effect displayed that BTW and EBB members stated more marriage-related goals compared to GEX members. The gender effect showed that women reported more marriage-related goals than men did. Simple main effects analysis of the interaction revealed that cohort differences were mainly found for women, with a continuous decrease from women of the oldest to women of the youngest cohort, $F(2,669)=18.98, p<.01$. No significant cohort differences emerged for men, $F<.81$, $n s$. Furthermore, gender differences emerged for the two older cohorts, with women mentioning more marriagerelated goals than men $(\mathrm{BTW}: F(1,669)=28.87, p<.01$, EBB: $F(1,669)=5.07, p<.05)$, whereas no gender differences were found for GEX members, $F<.49$, $n s$.

For goals related to health, men reported more such goals than women, independently of cohort membership, $F(1,669)=3.90, p<.05$, and neither a main effect of cohort nor a cohort by gender interaction were found, both $F$ s $<2.52$, ns.

For goals related to ideals and values, no effects of cohort or gender and no interaction effects emerged, all $F$ s $<2.51$, ns.

For self-related goals, a significant effect of cohort, $F(2$, $669)=4.52, p<.05$, and a cohort by gender interaction, $F(2,669)=3.55, p<.05$, was found. Post hoc analysis of the cohort effect indicated that BTW participants mentioned less self-related goals than GEX and EBB members. Simple main effects analysis of the interaction further revealed that cohort differences emerged primarily for men: GEX- and EBB-men mentioned more self-related goals than BTW-men, $F(2,669)=7.91, p<.01$. No cohort differences emerged for women, $F<.75$, ns.

The analysis of material goals revealed no differences between cohorts, $F(2,669)<.99$, $n s$, but material goals were mentioned more frequently by men than by women, $F(1,669)=6.55, p<.05$.

For goals related to relationships, a significant effect of cohort, $F(2,669)=28.35, p<.01$, of gender, $F(1$, $669)=4.63, p<.05$, and an interaction between the two factors, $F(2,669)=5.32, p<.01$, was found. Post hoc analysis of the cohort effect showed that BTW members mentioned less relationship goals than EBB and GEX members and EBB members mentioned less such goals than GEX members. The gender main effect indicated that men mentioned more relationship goals than women. Simple main effects further analyzing the interaction revealed that GEX-men mentioned more relationship goals than GEX-women, $F(1,669)=16.07, p<.01$, whereas there were no gender differences in the two older cohorts, both $F$ s $<.47$, ns.

For leisure goals, there were no effects of gender or cohort and no interaction, all $F$ s $<1.78$, ns.

For housing, a significant effect of cohort emerged, $F(2$, $669)=3.05, p<.05$, and post hoc tests indicated that GEX members mentioned more of these goals than BTW members. Furthermore, a significant effect of gender showed that women reported more goals related to housing than men did, $F(1,669)=9.06, p<.01$.

Neither gender or cohort main effects nor interaction emerged for the content category social participation, all $F \mathrm{~s}<2.39, n s$. 
Finally, for the content category other, a significant effect of cohort, $F(2,669)=3.15, p<.05$, of gender, $F(1$, $669)=3.91, p<.05$, as well as significant interaction between the two factors emerged, $F(2,669)=3.30$, $p<.05$. Post hoc analysis of the first effect showed that BTW members reported more such goals than EBB and GEX members. Moreover, men reported more such goals than women. Simple main effect analysis of the interaction showed cohort differences for men, with BTW-men mentioning more of these goals than their younger counterparts, $F(2,669)=5.19, p<.01$. Furthermore, gender differences emerged for the oldest cohort, with BTW-men reporting more goals than BTW-women, $F(1,669)=8.21$, $p<.01$. No gender differences were observed for the two younger cohorts, both $F \mathrm{~s}<1.23, n s$.

Taken together, effects of cohort were stronger than effects of gender (see $\eta^{2}$ in Table 2). In fact, effects of gender as well as interactive effects between gender and cohort were rather weak, with effect sizes $<.03$. Effects of cohort were strongest for family, $\eta^{2}=.11$, work, $\eta^{2}=.07$, and relationships, $\eta^{2}=.06$. Those effects indicated that indeed, at age 20, as expected, classical developmental tasks such as work and family were stronger concerns of
BTW and EBB participants than of GEX participants. Major concerns of GEX participants were related to relationships, but also to the self, education, and housing.

\section{Goal Process Variables and Life Satisfaction}

Participants' evaluations of goal success, control, and social sharedness at age 20 for each goal were averaged over all goals mentioned. These mean evaluations and life satisfaction at age 25 (see Table 3) were each subjected to a 3 (cohort) by 2 (sex) between-subjects ANOVA. For success, there was a cohort effect, $F(2,743)=3.57$, $p<.05$. Tukey post hoc tests showed that GEX members reported more success than BTW members. For control over goal attainment, there was a significant main effect of cohort, $F(2,743)=22.59, p<.001$, and a significant main effect of gender, $F(1,743)=9.33, p<.01$. Post hoc tests on the first main effect revealed that perceived control increased from the oldest cohort to the youngest. The main effect of gender indicated that men reported more control than women. For social sharedness of goals, there was a significant cohort effect, $F(2,743)=10.01, p<.001$, and a significant gender effect, $F(1,743)=5.63, p<.05$. Post

Table 3 Correlation matrix and descriptive statistics of goal evaluations at age 20 and life satisfaction at age 25

\begin{tabular}{|c|c|c|c|c|c|}
\hline & & 1 & 2 & 3 & 4 \\
\hline \multicolumn{6}{|c|}{$B T W$} \\
\hline 1. & Goal success & - & & & \\
\hline 2. & Control goal attainment & $.76^{* *}$ & - & & \\
\hline 3. & Goal social sharedness & .08 & $.15^{*}$ & - & \\
\hline \multirow[t]{3}{*}{4.} & Life satisfaction & $.21 * *$ & $.25^{* *}$ & $.29 * *$ & - \\
\hline & $M \mathrm{Men}^{\mathrm{a}}$ & $3.70(0.95)$ & $3.61(0.96)$ & $3.23(0.94)$ & 9.07 (1.93) \\
\hline & $M$ Women $^{\mathrm{a}}$ & $3.58(0.98)$ & $3.42(1.09)$ & $3.51(0.95)$ & $8.78(2.50)$ \\
\hline \multicolumn{6}{|c|}{$E B B$} \\
\hline 1. & Goal success & - & & & \\
\hline 2. & Control goal attainment & $.68 * *$ & - & & \\
\hline 3. & Goal social sharedness & .08 & .12 & - & \\
\hline \multirow[t]{3}{*}{4.} & Life satisfaction & $.30 * *$ & $.27 * *$ & .04 & - \\
\hline & $M \mathrm{Men}^{\mathrm{a}}$ & $3.82(0.80)$ & $3.97(0.66)$ & $3.37(0.88)$ & $8.88(2.08)$ \\
\hline & $M$ Women $^{\mathrm{a}}$ & $3.70(0.99)$ & $3.74(0.82)$ & $3.56(0.95)$ & $8.82(2.41)$ \\
\hline \multicolumn{6}{|c|}{$G E X$} \\
\hline 1. & Goal success & - & & & \\
\hline 2. & Control goal attainment & $.52 * *$ & - & & \\
\hline 3. & Goal social sharedness & .00 & -.03 & - & \\
\hline \multirow[t]{3}{*}{4.} & Life satisfaction & $.29 * *$ & .12 & -.11 & - \\
\hline & $M \mathrm{Men}^{\mathrm{a}}$ & $3.77(0.87)$ & $4.07(0.61)$ & $3.10(0.88)$ & $8.68(2.13)$ \\
\hline & $M$ Women $^{\mathrm{a}}$ & $3.93(0.88)$ & $3.93(0.72)$ & $3.11(0.93)$ & $9.20(1.90)$ \\
\hline
\end{tabular}

Note: Scales for goal evaluations ranged from 1 to 5 . The scale measuring life satisfaction ranged from 1 to 11

${ }^{a}$ Standard deviations are given in parentheses

$* p<.05,2$-tailed

$* * p<.01,2$-tailed 
hoc tests on the first factor revealed that BTW and EBB members reported more social sharedness than GEX members. The gender effect indicated that men reported less social sharedness than women. For life satisfaction at age 25 , the analysis revealed no significant differences between cohorts and sexes, all $F \mathrm{~s}<2.3$, ns.

We conducted path analyses using structural equation modeling to analyze relations between perceptions of goal attributes and life satisfaction across the three birth cohorts. The correlation matrices and descriptive statistics of the variables used in the path models are given in Table 3. The initial path model was constructed on previous research findings of variables such as goal success, controllability and social sharedness as predictors of life satisfaction. We tested the following model: goal success, controllability and social sharedness were expected to have a direct effect on life satisfaction. That is, a person's life satisfaction at age 25 is determined by success in goal attainment and perceptions of controllability and social sharedness of goals at age 20. Moreover, we expected direct effects of social sharedness and controllability on success therefore indicating an indirect effect of social sharedness and controllability on life satisfaction. The covariance between social sharedness and controllability was allowed to correlate and all variables in the model, except for the residual terms, were considered as having been observed. We used multiple-group analyses and testing of the chi-square differences of the models with free and invariant path coefficients to test whether the same model structure would fit for each of the three birth cohorts. First, the model was applied to each cohort separately, with free path coefficients. Figure 1 shows the initial model and the standardized path coefficients for the three cohorts.

For BTW participants, life satisfaction at age 25 was directly predicted by social sharedness of goals at age 20 ( $\beta=.26, p<.01)$ : higher perceived social sharedness of goals was related to higher levels of life satisfaction. Neither controllability of goal attainment $(\beta=.17$, $p=.06)$ nor goal success $(\beta=.05, p=.58)$ were directly related to life satisfaction. Controllability was, however, positively related to success $(\beta=.77, p<.01)$, indicating that higher levels of controllability were related to higher likelihood of success. Goal success and social sharedness were not related $(\beta=-.03, p=.45)$. For EBB participants, life satisfaction was directly predicted by success ( $\beta=.22, p<.01)$ : successful goal attainment at age 20 led to greater life satisfaction at age 25 . Neither social sharedness $(\beta=.00, p=.95)$ nor controllability $(\beta=.12$, $p=.16)$ were related to satisfaction. However, as for BTW participants, controllability was positively related to success $(\beta=.68, p<.01)$, indicating that higher levels of controllability were associated with higher rates of success. For GEX participants, a similar pattern emerged. Life satisfaction was predicted only by success $(\beta=.32$, $p<.01$ ) indicating that success in goal attainment at age 20 led to higher levels of life satisfaction at age 25. Neither social sharedness $(\beta=-.10, p=.08)$ nor controllability $(\beta=-.05, p=.47)$ predicted life satisfaction but controllability was positively related to success $(\beta=.52$, $p<.01)$.

The next step of the analyses consisted of putting the model under constraint, with invariant path coefficients across the birth cohorts. The fit statistics for the multiplegroup analyses are displayed in Table 4 . The paths from social sharedness to life satisfaction and to success, the paths from controllability to life satisfaction and to success, and the path from success to life satisfaction were set to be invariant across BTW, EBB, and GEX members. The chisquare difference between the models with free and invariant paths demonstrates that putting the model under constraint led to a significant deterioration of the model fit, $X^{2}(10)=30.81, p<.001$, therefore suggesting that the path coefficients are different between cohorts.

To identify the paths that were responsible for cohort differences concerning the impact of goal characteristics on life satisfaction, the coefficients of the three significant paths were set invariant in the second step of model comparison. The paths from social sharedness and from
Fig. 1 Path-analytic model of relations between perceptions of goal attributes and life satisfaction. Standardized path coefficients are reported for each cohort separately ( ${ }^{\mathrm{a}} \mathrm{BTW}$; ${ }^{\mathrm{b}} \mathrm{EBB} ;{ }^{\mathrm{c}}$ GEX). $* p<.05$; $* * p<.01$

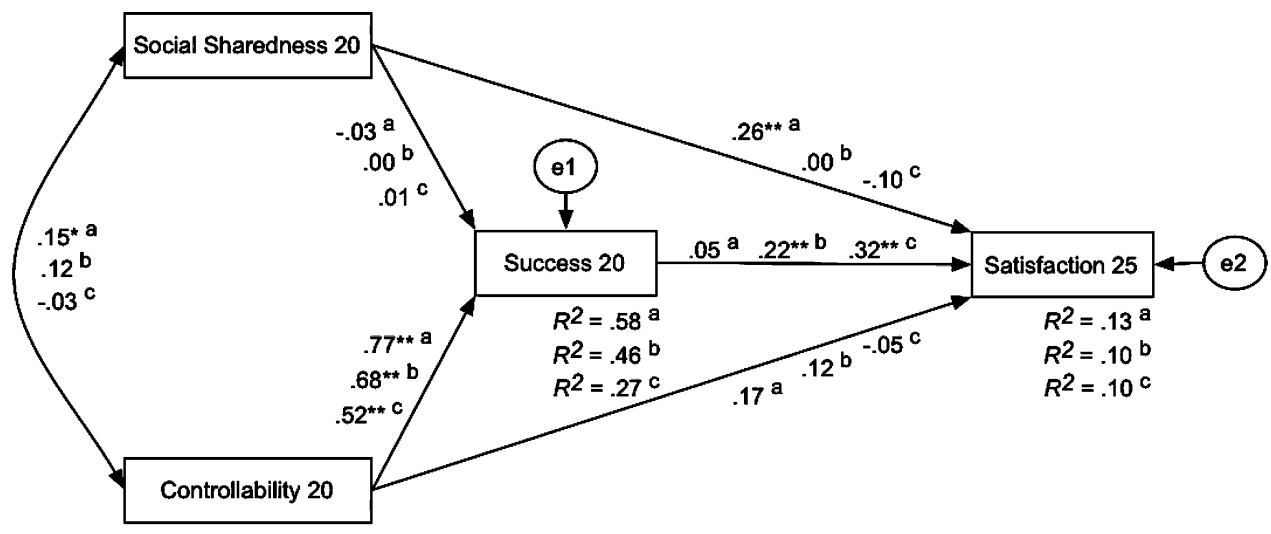


Table 4 Summary of fit statistics for multiple-group analyses

\begin{tabular}{llrrrr}
\hline Type of analysis & Chi-square & df & $p$ & CFI $^{\text {RMSEA (CI }}$ \\
\hline $\begin{array}{l}\text { 1. Invariant path coefficients } \\
\text { 2. Invariant path coefficients for Social sharedness to satisfaction, }\end{array}$ & 30.81 & 10 & .00 & .960 & $.053(.032-.075)$ \\
$\quad$ Success to satisfaction, Controllability to success & 28.23 & 6 & .00 & .958 & $.070(.046-.098)$ \\
$\begin{array}{l}\text { 3. Invariant path coefficients for Social sharedness to success, } \\
\quad \text { Controllability to satisfaction }\end{array}$ & 4.38 & 4 & .36 & .999 & $.011(.000-.057)$ \\
\begin{tabular}{l} 
4. Invariant path coefficients between EBB and GEX \\
\hline
\end{tabular} & 6.59 & 5 & .25 & .997 & $.021(.000-.058)$ \\
\hline
\end{tabular}

success to life satisfaction, and the path from controllability to success were supposed to be invariant across the groups. As expected, this restriction led again to a significant deterioration of the model fit, $X^{2}(6)=28.23$, $p<.001$, and showed that differences between cohorts are due to these significant path coefficients. In order to further support this finding, the two non-significant paths from social sharedness to success and from controllability to life satisfaction were put under constraint in step three of model comparison. As can be seen in Table 4, setting these two coefficients invariant across the cohorts did not lead to a significant deterioration of model fit, $X^{2}(4)=4.38$, $p=.36$, and strongly supports findings of step 3 , i.e., that the paths from social sharedness and from success to life satisfaction and from controllability to success differ between cohorts.

Step four consisted of setting again all regression coefficients under constraint and assuming them to be invariant, but only between the EBB and GEX cohort. Analysis of the chi-square difference between the model with free and invariant path coefficients supported the selection of the model with invariant parameters, because no deterioration in the model fit emerged, $X^{2}(5)=6.59, p=.25$. The impact of goal process variables on life satisfaction was similar for the two younger cohorts, and differed from the impact found for the BTW cohort.

Taken together, for members of the older cohort, perceived social sharedness of goals played an important role for reconstructed life satisfaction but not for members of the younger cohorts. For BTW members, social sharedness was the most important predictor of life satisfaction, whereas controllability of goal attainment and success played only minor roles for life satisfaction. For EBB and GEX participants, life satisfaction was uniquely determined by goal success. Perceived social sharedness of goals had no importance for well-being. Controllability was not directly related to life satisfaction of younger participants (or of older participants). But it was related to success in all three cohorts: Higher levels of controllability were associated with higher rates of success, which in turn were related to higher levels of life satisfaction for members of the EBB and GEX cohort.

\section{Discussion}

This study explored the influence of socio-historical changes related to increasing individualization on the reconstruction of individual development in young adulthood. Three birth cohorts were compared with respect to different aspects of goal pursuit (content and process) at age 20, life satisfaction at age 25 , and the relation between them.

For goal content, analyses revealed that BTW and EBB participants frequently reported pursuing goals that corresponded to classical developmental tasks such as starting a family or a career. Goals of GEX participants were related to relationships, the self, education, and housing. Thus, consistent with our expectations, personal goals of members of the youngest cohorts were more centered on the self and less focused on classical developmental tasks than those of older cohorts. These findings reflect well-documented aspects of societal change of the past decades (e.g., extension of education well into young adulthood, postponement of founding a family, more affluence) reflecting a greater focus on individualism today than $50-80$ years ago. Although a greater focus on the self may have risks, i.e., goals dealing with self-development come at the expense of other goals focusing on developmental demands and the environment (Arnett 2001; Salmela-Aro et al. 2001), we found no differences in life satisfaction between cohorts. Rather, it seems that the preoccupation of younger cohorts with self-development may be an indicator for new developmental tasks such as an increased pressure on selfrealization (Grob et al. 2001).

Cohort differences emerged also for reconstructions of goal process. As expected, members of the youngest cohort perceived more control over goal attainment than older cohorts. Thus, younger generations may see themselves more as agents in their lives than older generations do. They also perceived their goals as being less shared with members of their own cohort than members of the older cohorts did, indicating that today, goals of young adulthood are perceived as less socially shared than 50 years ago. Perceptions of social sharedness also decreased between the middle and the youngest cohort. Success in goal attainment did not differ between cohorts. 
Interestingly, younger participants perceived their goals as being less shared with members of their generation but the analysis of goal content revealed that they actually did share certain goals to a large extent (e.g., education and self-development). This is especially interesting with respect to goals related to self-development, indicating that younger people perceived themselves to be individualistic but shared the goal of individuality, which illustrates again the emergence of a new development task, i.e., an increased pressure on self-realization. Moreover, this finding indicates that young people's goals may not necessarily have become more diversified or de-standardized but may actually be quite similar. This is in line with Arnett's (2002) thesis, arguing that due to globalization, young people's goals around the world are becoming more similar, in the sense of an increasing focus on possibilities for self-development.

Path analyses using structural equation modeling revealed different "ways" to happiness, i.e., life satisfaction, in the different cohorts. For the BTW cohort, despite a direct influence of control on success, success was not a predictor of life satisfaction. Indeed, the only predictor of life satisfaction for that cohort was social sharedness. Thus, for BTW participants the very fact of pursuing the same goals that others were pursuing positively influenced life satisfaction. Grundmann (1996) found a similar phenomenon in analyzing the impact of father absence in two birth cohorts that experienced World War II as children. Father absence during childhood is a risk factor for sex-role development, but the study showed that normative father absence (i.e., when larger numbers of men experienced father absence due to the war) actually served as a protective factor against negative outcomes. However, our study cannot explain how social sharedness of goals operates. At least three explanations seem plausible. First, sharing important goals with others may increase the likelihood of social support, an importance resource for goal attainment (Diener et al. 1999). Second, perceived social sharedness may be an indicator of social integration, which may be the causal factor leading to increased life satisfaction. Third, perceived social sharedness may indicate to which degree one categorizes oneself as a member of a certain group (in our case as a member of a certain generation) and identifies with this group. In this case, low levels of identification may diminish life satisfaction. Further studies are needed to clarify this question.

In contrast to the BTW cohort, for EBB and GEX cohorts, the typical way to happiness is one that has often been described in the literature: success in attaining one's goals is a cause of later life satisfaction. Success, in turn, is partially caused by being in control of goal attainment. This is a classical individualistic pattern. It seems to have emerged with the postwar generation that came of age in the late 1960s. In other words, for these cohorts, there is a clear focus on success: success or failure determines life satisfaction. And since success is related to individual control, pressure on the individual self is higher than for the BTW cohort.

This study has some limitations. Perhaps the major limitation is the use of a retrospective cross-sectional design, implying a potential confound between age and cohort effects (Schaie 1965). Nevertheless, it seems implausible that age-related factors systematically distorted recollections of people from different cohorts so as to completely obscure cohort effects. Moreover, this study limitation is particularly difficult to overcome for the research question we chose, given the sheer time scale of the changes studied. So retrospective designs seem to be the only possibility to compare historical developmental contexts, and thus systematically document historical changes in psychological phenomena.

This study started by sketching a broad historical trend, subsequently deriving hypotheses about its probable influence on developmental contexts and showing how these contexts in turn influence goal setting in young adulthood. Results indicated that accounts of personal goals of young adulthood do indeed correspond to developmental tasks of that period but that those tasks as well as ways to master them are subject to socio-historical change. Thus, they add to a growing number of findings from historical developmental psychology (e.g., Elder et al. 1993; Grundmann 1996; Keller and Lamm 2005; Koops 1996) by illustrating the relevance of historical context for an understanding of human development and challenging the often implicit assumption that developmental processes are invariant over time.

Acknowledgment This study was supported by a grant (No. 500447766) from the Swiss National Science Foundation awarded to Alexander Grob.

\section{References}

Arnett, J. J. (1998). Learning to stand alone. The contemporary American transition to adulthood in cultural and historical. Human Development, 6, 295-315.

Arnett, J. J. (2000). Emerging adulthood: A theory of development from the late teens through the twenties. American Psychologist, $55,469-480$.

Arnett, J. J. (2001). Conceptions of the transition to adulthood: Perspectives from adolescence through midlife. Journal of Adult Development, 8, 133-143.

Arnett, J. J. (2002). The psychology of globalization. American Psychologist, 57, 774-783.

Austin, J. T., \& Vancouver, J. B. (1996). Goal constructs in psychology: Structure, process, and content. Psychological Bulletin, 120, 338-375.

Baltes, P. B., Reese, H. W., \& Lipsitt, L. P. (1980). On life-span developmental research paradigms: Retrospects and prospects. 
In P. B. Baltes \& K. W. Schaie (Eds.), Life-span developmental psychology: Personality and socialization (pp. 365-395). New York: Academic Press.

Bangerter, A., Grob, A., \& Krings, F. (2001). Personal goals at age 25 in three generations of the twentieth century: Young adulthood in historical context. Swiss Journal of Psychology, 60, 59-64.

Brandtstädter, J. (1984). Personal and social control over development: Some implications of an action perspective in life-span developmental psychology. In P. B. Baltes \& O. G. Brim, Jr. (Eds.), Life-span development and behavior (Vol. 6, pp. 1-32). New York: Academic Press.

Brose, H.-G. (2003). Die Subversion der Institution-über Riesters Rente, lebenslanges Lernen und andere Kleinigkeiten [Subversion of the institution-about Riesters pension, life-long learning and other minor details]. In J. Allmendinger (Ed.), Entstaatlichung und soziale Sicherheit. Verhandlungen des 31. Kongresses der Deutschen Gesellschaft für Soziologie in Leipzig 2002. Opladen: Leske \& Budrich.

Brunstein, J. C. (1993). Personal goals and subjective well-being: A longitudinal study. Journal of Personality and Social Psychology, 65, 1061-1070.

Brunstein, J. C., Schultheiss, O. C., \& Maier, G. W. (1999). The pursuit of personal goals. A motivational approach to well-being and life adjustment. In J. Brandtstädter \& R. M. Lerner (Eds.), Action and self-development. Theory and research through the life span (pp. 169-196). Thousand Oaks: Sage.

Cohen, P., \& Cohen, J. (2001). Life values and mental health in adolescence. In P. Schmuck \& K. M. Sheldon (Eds.), Life goals and well-being: Towards a positive psychology of human striving (pp. 167-181). Seattle, Toronto, Bern, Göttingen: Hogrefe.

Coleman, J. C., \& Hendry, L. B. (1999). The nature of adolescents. London: Routledge.

DeNeve, K. M., \& Cooper, H. (1998). The happy personality: A metaanalysis of 137 personality traits and subjective well-being. Psychological Bulletin, 124, 197-229.

Diener, E., \& Fujita, F. (1995). Resources, personal strivings, and subjective well-being: A nomothetic and idiographic approach. Journal of Personality and Social Psychology, 68, 926-935.

Diener, E., Suh, E. M., Lucas, R. E., \& Smith, H. L. (1999). Subjective well-being: Three decades of progress. Psychological Bulletin, 125, 276-302.

Elder, G. H., Jr. (1985). Life course dynamics: Trajectories and transitions, 1968-1980. Ithaca, NY: Cornell University Press.

Elder, G. H., Jr., Modell, J., \& Parke, R. D. (1993). Studying children in a changing world. In G. H. Elder, Jr., J. Modell, \& R. D. Parke (Eds.), Children in time and place: Developmental and historical insights (pp. 3-23). New York: Cambridge University Press.

Emmons, R. A. (1986). Personal strivings: An approach to personality and subjective well-being. Journal of Personality and Social Psychology, 51, 1058-1068.

Emmons, R. A. (1989). The personal striving approach to personality. In L. A. Pervin (Ed.), Good concepts in personality and social psychology (pp. 87-126). Hillsdale, NJ: Erlbaum.

Grob, A., Krings, F., \& Bangerter, A. (2001). Life markers in biographical narratives of people from three cohorts: A life span perspective in its historical context. Human Development, 44, 171-190.

Grob, A., Little, T. D., \& Wanner, B. (1999). Control judgements across the life-span. International Journal of Behavioral Development, 23, 833-854.

Grundmann, M. (1996). Historical context of father absence: Some consequences for the family formation of German men. International Journal of Behavioral Development, 19, 415-431.

Habermas, T., \& Bluck, S. (2000). Getting a life: The emergence of a life story in adolescence. Psychological Bulletin, 126, 748-769.
Hareven, T. K. (1986). Historical changes in the social construction of the life course. Human Development, 29, 171-180.

Havighurst, R. J. (1948). Developmental tasks and education. New York: David McKay.

Held, T. (1986). Institutionalization and de-institutionalization of the life course. Human Development, 29, 157-162.

Heckhausen, J. (1999). Developmental regulation in adulthood. Agenormative and sociostructural constraints as adaptive challenges. Cambridge: Cambridge University Press.

Heckhausen, J., \& Krüger, J. (1993). Developmental expectations for the self and most other people: Age grading in three functions of social comparison. Developmental Psychology, 29, 539-548.

Kasser, T., \& Ryan, R. M. (1993). A dark side of the American dream: Correlates of financial success as a central life aspiration. Journal of Personality and Social Psychology, 65, 410-422.

Keller, H., \& Lamm, B. (2005). Parenting as the expression of sociohistorical time: The case of German individualisation. International Journal of Behavioral Development, 29, 238-246.

Kohli, M. (1985). Die Institutionalisierung des Lebenslaufes [The institutionalization of the life course]. Kölner Zeitschrift für Soziologie und Sozialpsychologie, 37, 1-29.

Kohli, M. (2000). Arbeit im Lebenslauf: Alte und Neue Perspektiven [Work in the life course: Old and new perspectives]. In J. Kocka \& C. Offe (Eds.), Geschichte und Zukunft der Arbeit (pp. 362382). Frankfurt: Campus.

Koops, W. (1996). Historical developmental psychology: The sample case of paintings. International Journal of Behavioral Development, 19, 393-413.

Lang, F. R., \& Heckhausen, J. (2001). Perceived control over development and subjective well-being: Differential benefits across adulthood. Journal of Personality and Social Psychology, $81,509-523$.

Lapierre, S., Bouffard, L., \& Bastin, E. (1997). Personal goals and subjective well-being in later life. International Journal of Aging and Human Development, 45, 287-303.

Little, B. R. (1989). Personal project analysis: Trivial pursuits, magnificent obsessions, and the search for coherence. In D. M. Buss \& N. Cantor (Eds.), Personality psychology. Recent trends and emerging directions (pp. 15-31). New York, NY: Springer.

Mannheim, K. (1952). The problem of generations. In K. Mannheim (Ed.), Essays on the sociology of knowledge (pp. 276-321). London: Routledge \& Keegan Paul.

Mayer, K. U. (2004). Whose lives? How history, societies, and institutions define and shape life courses. Research in Human Development, 1, 161-187.

McAdams, D. P. (1996). Narrating the self in adulthood. In J. E. Birren, G. M. Kenyon, J.-E. Ruth, J. J. F. Schroots, \& T. Svensson (Eds.), Aging and biography: Explorations in adult development (pp. 131-148). New York, NY: Springer.

Nurmi, J.-E. (1991). How do adolescents see their future? A review of the development of future orientation and planning. Developmental Review, 11, 1-59.

Nurmi, J.-E. (1992). Age differences in adult life goals, concerns, and their temporal extension: A life course approach to futureoriented motivation. International Journal of Behavioral Development, 15, 487-508.

Oerter, R., \& Montada, L. (1998). Entwicklungspsychologie [Developmental psychology]. Weinheim: Beltz.

Palys, T. S., \& Little, B. R. (1983). Perceived life satisfaction and the organization of personal project systems. Journal of Personality and Social Psychology, 44, 1221-1230.

Riley, M. W. (1986). The dynamisms of life stages: Roles, people and age. Human Development, 29, 150-156.

Salmela-Aro, K., Pennanen, R., \& Nurmi, J.-E. (2001). Self-focused goals: What they are, how they function, and how they relate to well-being. In P. Schmuck \& K. M. Sheldon (Eds.), Life goals 
and well-being: Towards a positive psychology of human striving (pp. 148-166). Seattle, Toronto, Bern, Göttingen: Hogrefe.

Schaie, K. W. (1965). A general model for the study of developmental problems. Psychological Bulletin, 64, 92-107.

Schroots, J. J. F., \& Assink, M. H. J. (2005). Portraits of life: Patterns of events over the life span. Journal of Adult Development, 12, 183-198.

Settersten, R. A., Jr. (1997). The salience of age in the life course. Human Development, 40, 257-281.
Smith, J. (1996). Planning about life: A social-interactive perspective. In P. B. Baltes \& U. M. Staudinger (Eds.), Interactive minds (pp. 242-275). Cambridge: Cambridge University Press.

Tindale, R. S., \& Kameda, T. (2000). Social sharedness as a unifying theme for information processing in groups. Group Processes and Intergroup Relations, 3, 123-140.

Uchida, Y., Norasakkunkit, V., \& Kitayama, S. (2004). Cultural constructions of happiness: Theory and empirical evidence. Journal of Happiness Studies, 5, 223-239. 